\title{
INFLUENCE OF INSPIRATORY MUSCLE WARM-UP EXERCISE ON FIELD HOCKEY DRAG-FLICK AND SHOOTING PERFORMANCE
}

\author{
Nahsen Avci, \\ Mustafa Özdali, \\ Mehmet Vural \\ Gaziantep University, \\ Faculty of Sport Science, \\ Gaziantep, Turkey
}

\begin{abstract}
:
The aim of this study is to examine the effect of inspiratory muscle exercise on drag-flick and shooting performance in hockey. For this purpose, 30 individuals engaged in hockey sports participated in the study as an experimental group. The subjects were applied three inspiratory muscle warm-up exercises (maximal inspiratory pressure, MIP): at 5\% intensity (placebo) and 40\% intensity (RWU), with 30 breaths $x 2$ sets and 1 minute rest between sets, first without warming up. After each test, 20 shots drag-flick and 20 shots were performed at the hockey goal, whose scoring was prepared before. The data obtained were analyzed in SPSS 22.0 program. After testing for normality and homogeneity, one-way analysis of variance and LSD correction were performed for repeated measurements. According to the one-way analysis of variance test in repeated measurements; in the drag-flick performance test, a significant difference in favor of the RWU application was observed between the RWU application and placebo and no warming applications $(\mathrm{p}<0.05)$. In the shooting performance test, there was a significant difference between RWU application and placebo and no warm-up applications in favor of RWU application ( $\mathrm{p}<0.05$ ). In the drag-flick performance test, when the change of the fatigue scores of the subjects between the applications was examined; there was a significant difference in favor of RWU application $(\mathrm{p}<0.05)$. Fatigue was found to be less in RWU application. When the change of fatigue scores between applications in the shooting performance test was examined; there was a significant difference between RWU application and placebo and no warming applications in favor of RWU application ( $p<0.05)$. Fatigue was found to be less in RWU application. As a result, it can be said that inspiratory muscle exercise has a positive effect on drag-flick and shooting performance in hockey.
\end{abstract}

Keywords: hockey, respiratory, inspiratory, exercise, drag-flick, flick

i Correspondence: email ozdalm@hotmail.com 


\section{Introduction}

One of the basic elements is oxygen which necessary to continue life functions on earth. In addition, oxygen not only provides the energy required for living and exercises but is an important factor to be considered in order to achieve success in sport branches. The functioning of the respiratory system mechanically depends substantially on the capacity of the respiratory muscles (Özdal, 2016). The general warm-up has a potentially positive effect on short-term performance (Bishop, 2003). This may be because of reduction in joint stiffness (Wright \& Johns, 1961), increased neurotransmission (Karvonen, 2015), and differences in the relationship between power and acceleration (Ranatunga et al., 1987). In-depth investigation of the effects of a general warm-up on respiratory muscle activity has recently been performed, and the therapeutic and beneficial effects were noted by the researchers (Jung \& Kim, 2015). Previous studies had been showed that the inspiratory muscle warp-up had positive effect on some physical and physiological parameters (Arend et al., 2015; Jung \& Kim, 2015; Özdal, 2016; Özdal et al., 2016; Özdal et al., 2014).

The fact that the players who play in different positions in hockey move differently and change positions frequently in the field make it necessary for them to do aerobic training in addition to other training types (Bale, 1983). Elite hockey players have to improve their interval endurance and aerobic capacity for their sportive performance (Elferink-Gemser et al., 2011). In this way, it is thought that the inspiratory muscle warmup will have a positive effect on hockey-specific skills. Because the adaptation of the respiratory system to exercise directly affects the performance (Ekelund, 1967; Morse et al., 1949). We hypothesized that inspiratory muscle warm-up positively affects the dragflick and shooting performance in hockey. With this background this study aims to investigate the effect of inspiratory muscle exercise on drag-flick and shooting (hit) performance in hockey.

\section{Material and Method}

\subsection{Design and Participants}

The study was designed according to experimental design with control application in repeated measurements. Thirty volunteer male hockey players between the ages of 19-28 participated in the study (Table 2.1). In order to determine the number of subjects, a priori test was applied with GPower 3.1 program. Before the study, a voluntary consent form was obtained from the subjects. Three applications were performed by giving a randomized trail card: without warm-up [no-warm-up], 5\% placebo [placebo application] and 40\% test application [RWU application]. The respiratory muscle strength (MIP) of the subjects was measured and necessary explanations were made for the study. The next three days, at the same time (18.00-20.00), subject randomly participated in three applications. 
Table 2.1: Descriptive statistics of the participants

\begin{tabular}{|l|c|c|c|c|}
\hline & Min. & Max. & Mean & Std. D. \\
\hline Age (year) & 19,00 & 28,00 & 21,50 & 2,98 \\
\hline Height $(\mathrm{cm})$ & 166,00 & 177,00 & 172,88 & 3,52 \\
\hline Weight $(\mathrm{kg})$ & 58,00 & 80,00 & 68,13 & 6,49 \\
\hline
\end{tabular}

\subsection{Procedures}

\subsubsection{Inspiratory warm-up protocol}

Inspiratory muscle warming was performed with the inspiratory muscle training device, 30 breaths $\times 2$ sets of $40 \%$ MIP and 1-minute rest between sets in experimental section. In placebo, participants performed a warm-up of the respiratory muscle with 30 breaths $\times 2$ sets of 5\% MIP and 1-minute rest between sets (Özdal, 2016).

\subsubsection{Respiratory muscle strength measurement (MIP)}

Electronic respiratory pressure meter (Pocket Spiro MPM-100, Medical Electronic Construction R\&D, Brussels, Belgium) was used for MIP calculation according to the 2002 guidelines of the American Thoracic Society and European Respiratory Society. For MIP measurement, participants performed maximal expiration, immediately following which they were asked to perform maximal inspiration for 1- $3 \mathrm{~s}$. The measurements were repeated until the difference between the best two measurements was $5 \mathrm{cmH} 2 \mathrm{O}$, and the best result was recorded in terms of $\mathrm{cmH} 2 \mathrm{O}$ (Kera, 2002).

\subsubsection{Hockey drag-flick and shot performance test}

Participants performed drag-flick and shooting techniques, which are basic hockey techniques, towards the scored goal after inspiratory warm-up. The average score they got from five applications was taken into account (Smith et al., 2001).

\subsubsection{Goal and scoring}

A standard hockey goal with a width of $3.66 \mathrm{~m}$ and a height of $2.14 \mathrm{~m}$ was used for shooting. From each goalpost, the inside of the castle is divided into 3 parts by pulling a tape from the upper pole to the point reached by measuring $40 \mathrm{~cm}$ into the castle. The shots were made from the penalty point $6.5 \mathrm{~m}$ from the goal. Shots hitting the area between the goalposts and the band are 2 points, shots hitting the middle of the goal are 1 point and shots that hit out of goal are scored without points (Smith et al., 2001).

\subsubsection{Drag-flick performance test}

The athletes firstly shot 20 drag-flicks without any warm-up exercise and without any measurement. The scores obtained in the shots are noted (Smith et al., 2001). In the second and third stages, participants performed inspiratory muscle strength training randomly 30 breaths $\times 2$ sets of $40 \%$ MIP and 1-minute rest between sets for experimental, 30 breaths x 2 sets of 5\% MIP and 1-minute rest between sets for placebo. After training they performed 20 shots (Drag-flick). The points scored in the shots were noted. 


\subsubsection{Hit performance test}

The athletes firstly shot 20 drag-flicks without any warm-up exercise and without any measurement. The scores obtained in the shots are noted. In the second and third stages, participants performed inspiratory muscle strength training randomly 30 breaths $x 2$ sets of $40 \%$ MIP and 1-minute rest between sets for experimental, 30 breaths $\times 2$ sets of $5 \%$ MIP and 1-minute rest between sets for placebo. After training they performed 20 shots (Hit shot). The points scored in the shots were noted.

\subsection{Statistical analysis}

SPSS 22.0 program was used for statistical analysis. The obtained shot data were evaluated as total and five shots and the difference between the last 5 shots and the first 5 shots was accepted as the fatigue index and recorded as a separate parameter. After testing for normality and homogeneity, one-way analysis of variance for repeated measurements and LSD correction were used. Values are presented as minimum, maximum, mean and standard deviation and were analyzed at 0.05 significance level.

\section{Result}

In our study, 30 volunteer hockey athletes were performed 3 different intensity respiratory muscle training and at the end of each application, drag-flick and shot were performed. Analysis and presentation of the effect of respiratory muscle training on dragflick and shot hit is given in this section. The applications were made sequentially as placebo, RWU and before warming up.

Table 3.1: The change of scores obtained in the drag flick test between applications

\begin{tabular}{|l|c|c|c|c|}
\hline & Mean & Std.D. & F & p \\
\cline { 1 - 3 } No-warm-up & 20,75 & 4,59 & \multirow{2}{*}{10.814} & \multirow{2}{*}{0.002} \\
\cline { 1 - 3 } Placebo & 22,88 & 2,70 & & \\
\hline RWU & $27,88^{\mathrm{ab}}$ & 2,85 & \\
\cline { 1 - 2 } \\
$\begin{array}{l}\text { RWU: respiratory warm-up; a: significance differences with no-warm-up; b: significance differences } \\
\text { with placebo; c: significance differences with RWU }\end{array}$
\end{tabular}

Table 3.1 shows the change of the average scores obtained in the drag flick test between applications. There was no significant difference between applications according to statistical test $(\mathrm{p}<0.05)$.

Table 3.2: The change of the average scores of the first 5 shots between applications in the drag flick test

\begin{tabular}{|l|c|c|c|c|}
\hline & Mean & Std.D & F & p \\
\hline No-warm-up & 6,00 & 2,07 & \multirow{2}{*}{0.681} & \multirow{2}{*}{0.498} \\
\hline Placebo & 5,38 & 1,06 & \\
\cline { 1 - 2 } & 6,25 & 1,04 & & \\
\hline
\end{tabular}

RWU: respiratory warm-up; a: significance differences with no-warm-up; b: significance differences with placebo; c: significance differences with RWU 
Table 3.2 shows the change of the average score of the first 5 shots in the drag flick test between applications. According to the statistical analysis there was no significant difference between applications according to statistical test $(p>0.05)$.

Table 3.3: The change of the average scores of the second 5 shots between applications in the drag flick test

\begin{tabular}{|c|c|c|c|c|}
\hline & Mean & Std.D & $\mathbf{F}$ & $\mathrm{p}$ \\
\hline No-warm-up & 5,63 & 1,19 & \multirow{3}{*}{5.401} & \multirow{3}{*}{0.028} \\
\hline Placebo & 6,38 & 1,19 & & \\
\hline RWU & $7,75^{\mathrm{ab}}$ & 1,28 & & \\
\hline
\end{tabular}

Table 3.3 shows the change of the average score of the second 5 shots in the drag flick test between applications. According to the statistical analysis there was significant differences between RWU, placebo and no-warm-up applications in favor of RWU ( $\mathrm{p}<$ $0.05)$.

Table 3.4: The change of the average scores of the third 5 shots between applications in the drag flick test

\begin{tabular}{|c|c|c|c|c|}
\hline & Mean & Std.D & $\mathbf{F}$ & $\mathrm{p}$ \\
\hline No-warm-up & 4,13 & 2,03 & \multirow{3}{*}{10.492} & \multirow{3}{*}{0.004} \\
\hline Placebo & $6,38^{a}$ & 1,69 & & \\
\hline RWU & $7,75^{\mathrm{ab}}$ & 1,83 & & \\
\hline
\end{tabular}

Table 3.4 shows the change of the average score of the third 5 shots in the drag flick test between applications. According to the statistical analysis there was significant difference between RWU, placebo and no-warm-up applications in favor of RWU; between placebo and no-warm-up applications in favor of placebo $(\mathrm{p}<0.05)$.

Table 3.5: The change of the average scores of

the last 5 shots between applications in the drag flick test

\begin{tabular}{|c|c|c|c|c|}
\hline & Mean & Std.D & $\mathbf{F}$ & p \\
\hline No-warm-up & 5,00 & 1,60 & \multirow{3}{*}{4.073} & \multirow{3}{*}{0.048} \\
\hline Placebo & 4,75 & 1,49 & & \\
\hline RWU & $6,13^{\mathrm{ab}}$ & 0,35 & & \\
\hline
\end{tabular}

Table 3.5 shows the change of the average score of the last 5 shots in the drag flick test between applications. According to the statistical analysis there was significant difference between RWU, placebo and no-warm-up applications in favor of RWU $(p<0.05)$. 
Table 3.6: The change in the fatigue scores of

the subjects between the applications in the drag flick test

\begin{tabular}{|l|c|c|c|c|}
\hline & Mean & Std.D & F & p \\
\cline { 1 - 2 } No-warm-up & $-1,00$ & 1,31 & \multirow{2}{*}{4.942} & \multirow{2}{*}{0.044} \\
\cline { 1 - 3 } Placebo & $-0,63$ & 1,06 & & \\
\hline RWU & $-0,13^{\mathrm{ab}}$ & 1,25 & & \\
\hline
\end{tabular}

RWU: respiratory warm-up; a: significance differences with no-warm-up; b: significance differences with placebo; c: significance differences with RWU

Table 3.6 shows the change in the fatigue scores of the subjects between the applications in the drag flick test. According to the statistical analysis there was significant difference between RWU, placebo and no-warm-up applications in favor of RWU $(p<0.05)$. It was determined that fatigue decreased more in RWU application.

Table 3.7: The change of average scores

between applications in the hit shot test

\begin{tabular}{|l|c|c|c|c|}
\hline & Mean & Std.D & F & p \\
\cline { 1 - 3 } No-warm-up & 21,13 & 3,98 & \multirow{2}{*}{6.958} & \multirow{2}{*}{0.010} \\
\cline { 1 - 3 } Placebo & 19,88 & 2,59 & & \\
\hline RWU & $25,50^{\mathrm{ab}}$ & 3,34 & & \\
\hline
\end{tabular}

RWU: respiratory warm-up; a: significance differences with no-warm-up; b: significance differences with placebo; c: significance differences with RWU

Table 3.7 shows the change of average scores between applications in the hit shot test. According to the statistical analysis there was significant difference between RWU, placebo and no-warm-up applications in favor of RWU $(\mathrm{p}<0.05)$.

Table 3.8: The change of the average scores of the first 5 shots between applications in the hit shot test

\begin{tabular}{|l|c|c|c|c|}
\hline & Mean & Std.D & F & p \\
\hline No-warm-up & 5,88 & 1,13 & \multirow{2}{*}{1.472} & \multirow{2}{*}{0.265} \\
\cline { 1 - 3 } Placebo & 4,88 & 0,99 & & \\
\hline RWU & 5,75 & 1,49 & \\
\cline { 1 - 2 } $\begin{array}{l}\text { RWU: respiratory warm-up; a: significance differences with no-warm-up; b: significance differences } \\
\text { with placebo; c: significance differences with RWU }\end{array}$
\end{tabular}

Table 3.8 shows the change of the average scores of the first 5 shots between applications in the hit shot test. According to the statistical analysis there was no significant differences between applications ( $p>0.05$ ). 
Table 3.9: The change of the average scores of

the second 5 shots between applications in the hit shot test

\begin{tabular}{|l|c|c|c|c|}
\hline & Mean & Std.D & F & p \\
\cline { 1 - 3 } No-warm-up & 5,623 & 2,07 & \multirow{2}{*}{4.229} & \multirow{2}{*}{0.048} \\
\cline { 1 - 3 } Placebo & 5,88 & 1,36 & & \\
\cline { 1 - 3 } & $7,50^{\mathrm{ab}}$ & 2,14 & & \\
\hline
\end{tabular}

RWU: respiratory warm-up; a: significance differences with no-warm-up; b: significance differences with placebo; c: significance differences with RWU

Table 3.9 shows the change of the average scores of the second 5 shots between applications in the hit shot test. According to the statistical analysis there was significant differences between RWU, placebo and no-warm-up applications in favor of RWU ( $p<$ $0.05)$.

Table 3.10: The change of the average scores

of the third 5 shots between applications in the hit shot test

\begin{tabular}{|l|c|c|c|c|}
\hline & Mean & Std.D & F & p \\
\hline No-warm-up & 4,63 & 1,60 & & \multirow{2}{*}{4.661} \\
\cline { 1 - 2 } Placebo & 4,88 & 1,25 & 0.045 \\
\cline { 1 - 3 } RWU & $6,75^{\mathrm{ab}}$ & 1,39 & & \\
\hline
\end{tabular}

RWU: respiratory warm-up; a: significance differences with no-warm-up; b: significance differences with placebo; c: significance differences with RWU

Table 3.10 shows the change of the average scores of the third 5 shots between applications in the hit shot test. According to the statistical analysis there was significant differences between RWU, placebo and no-warm-up applications in favor of RWU ( $p<$ $0.05)$.

Table 3.11: The change of the average scores of the last 5 shots between applications in the hit shot test

\begin{tabular}{|l|c|c|c|c|}
\hline & Mean & Std.D & F & p \\
\cline { 1 - 2 } No-warm-up & 5,00 & 1,60 & & \multirow{2}{*}{1.985} \\
\cline { 1 - 2 } Placebo & 4,25 & 1,04 & 0.199 \\
\cline { 1 - 3 } & 5,50 & 1,31 & & \\
\hline
\end{tabular}

RWU: respiratory warm-up; a: significance differences with no-warm-up; b: significance differences with placebo; c: significance differences with RWU

Table 3.11 shows the change of the average scores of the last 5 shots between applications in the hit shot test. According to the statistical analysis there was no significant differences between applications ( $p>0.05$ ). 
Table 3.12: The change in the fatigue scores

of the subjects between the applications in the hit shot test

\begin{tabular}{|l|c|c|c|c|}
\hline & Mean & Std.D & F & p \\
\cline { 1 - 3 } No-warm-up & $-0,88$ & 0,83 & \multirow{2}{*}{5.847} & \multirow{2}{*}{0.036} \\
\hline Placebo & $-0,63$ & 1,30 & & \\
\hline RWU & $-0,25 \mathrm{ab}$ & 0,46 & & \\
\hline
\end{tabular}

RWU: respiratory warm-up; a: significance differences with no-warm-up; b: significance differences with placebo; c: significance differences with RWU

Table 3.12 shows the change in the fatigue scores of the subjects between the applications in the hit shot test. According to the statistical analysis there was significant differences between RWU, placebo and no-warm-up applications in favor of RWU ( $<<0.05)$. It was determined that fatigue decreased more in RWU application.

\section{Discussion and Conclusion}

This study was conducted to examine whether inspiratory muscle training has an effect on drag-flick and shot (hit) performance in male hockey athletes. With this purpose the study was designed according to experimental design with control application with repeated measurements. Three applications were performed by giving a randomized trail card: without warm-up [no-warm-up], 5\% placebo [placebo application] and $40 \%$ test application [RWU application]. The respiratory muscle strength (MIP) of the subjects was measured and necessary explanations were made for the study. The next three days, at the same time (18.00-20.00), subject randomly participated in three applications.

In our study, when we examine the change of average scores obtained in the dragflick test between applications; there was significant difference between RWU, placebo and no-warm-up applications in favor of RWU. When the shots are examined separately generally in all test stages (second, third and last 5 shots) of drag-flick testing significant differences were detected between RWU, placebo and no-warm-up applications in favor of RWU apart from first 5 shots application. When the change between the fatigue scores of the subjects in the drag-flick test was examined; significant differences was determined between RWU, placebo and no-warm-up applications in favor of RWU. It was determined that fatigue decreased more in RWU application.

When examining the change of average scores obtained in the shot (hit) test between applications; there was significant difference between RWU, placebo and nowarm-up applications in favor of RWU. In evaluating every five shots performed at intervals (second, and third 5 shots) significant differences were detected between RWU, placebo and no-warm-up applications in favor of RWU apart from first and last 5 shots (hit shot) application. When looking at the change of fatigue scores between applications in the hit test; significant differences was determined between RWU, placebo and nowarm-up applications in favor of RWU. It was determined that fatigue decreased more in RWU application. 
Previous studies have examined effect of inspiratory muscle training in different sport branches (basketball, football, rowing etc.). With the data obtained in the investigations, inspiratory muscle training has been shown that inspiratory muscle exercise provides slower and deep breathing. It increases the stability of the core muscles, which helps the athletes to perform their movements better and prevent the risk of injury (McConnell AK, 2011). Although there are researches on inspiratory muscle training in different sports branches, there are very few studies on the hockey branch.

Recent studies have showed that the inspiratory muscle training performed with different intensities have positive effect on performance (general, branch specific), respiratory functions, respiratory muscles strength (MIP-MEP) in sedentary and athletes individuals (Hartz et al., 2018; Romer et al., 2002; Volianitis et al., 2001; Williams et al., 2002). Additionally these researches, inspiratory muscle strength training carried out in disability persons (Okrzymowska et al., 2019; Vural et al., 2019), in children (Öztütüncü \& Özdal, 2019) and in patients (Dall'Ago et al., 2006; Enright et al., 2004; Harver et al., 1989).

Respiratory load increases with high intensity exercise. While this situation affects the respiratory ability of the athlete, it causes the respiratory muscles to fatigue and insufficient oxygen transfer to the tissues. For this reason, fatigue symptoms are observed in athletes. Fatigue of the respiratory muscles means that up to $15 \%$ of the athlete's total energy efficiency is lost (Harms et al., 2000; Lomax \& McConnell, 2003; Sheel et al., 2001; St Croix et al., 2000). Considering the comparisons between applications in the present study; it can be concluded that in comparison of the last five shots and overall fatigue scores, in which fatigue began to increase and athlete performance decreased, significant results in favor of RWU showed effects such as increased alveolar ventilation and decreased alveolar carbon dioxide, thus it decreases respiratory muscle fatigue and reduces the fatigue of the athlete during exercise. In summary, it can be said that the increase in muscle strength of the athlete, who is less metabolically tired, makes the dragflick or shot much harder, and the improvement in the breathing rhythm makes the shot more accurate.

In conclusion, when the tests and muscle exercise applications and data were analyzed, a significant difference was found in favor of inspiratory muscle exercise (RWU) in general. It can be thought that inspiratory muscle exercise can have a positive effect on drag-flick and shot hit performance in hockey.

\section{Conflict of Interest}

There are no potential conflicts of interest between authors of this article.

\section{About the Authors}

Nahsen Avcı is a Master of Science degree student at Gaziantep University, Turkey. This study is a part of Nahsen Avcr's master thesis.

Mustafa Özdal is an associate professor at Gaziantep University, Turkey. 
Mehmet Vural is researcher at the Faculty of Sports Sciences at Gaziantep University, Turkey.

\section{References}

Arend, M., Mäestu, J., Kivastik, J., Rämson, R., \& Jürimäe, J. (2015). Effect of inspiratory muscle warm-up on submaximal rowing performance. Journal of Strength and Conditioning Research, 29(1), 213-218.

Bale, P. (1983). The physiques, fitness and strength of top class women hockey players. https://pascal-

francis.inist.fr/vibad/index.php?action=getRecordDetail\&idt=PASCAL83X039331 2

Bishop, D. (2003). Warm Up II Performance Changes Following Active Warm Up and How to Structure the Warm Up. In Sports Med (Vol. 33, Issue 7).

Dall'Ago, P., Chiappa, G. R. S., Guths, H., Stein, R., \& Ribeiro, J. P. (2006). Inspiratory muscle training in patients with heart failure and inspiratory muscle weakness: A randomized trial. Journal of the American College of Cardiology, 47(4), 757-763.

Ekelund, L. -G. (1967). Circulatory and Respiratory Adaptation during Prolonged Exercise of Moderate Intensity in the Sitting Position. Acta Physiologica Scandinavica, 69(4), 327-340.

Elferink-Gemser, M., Visscher, C., Lemmink, K., Mulder, T., Elferink-Gemser, M. T., Lemmink, K. A. P. M., \& Mulder, T. W. (2011). Relation between multidimensional performance characteristics and level of performance in talented youth field hockey players. Journal of Sports Sciences, 22(11-12), 1053-1063.

Enright, S., Chatham, K., Ionescu, A. A., Unnithan, V. B., \& Shale, D. J. (2004). Inspiratory muscle training improves lung function and exercise capacity in adults with cystic fibrosis. Chest, 126(2), 405-411.

Harms, C. A., Wetter, T. J., St. Croix, C. M., Pegelow, D. F., \& Dempsey, J. A. (2000). Effects of respiratory muscle work on exercise performance. Journal of Applied Physiology, 89(1), 131-138.

Hartz, C. S., Sindorf, M. A. G., Lopes, C. R., Batista, J., \& Moreno, M. A. (2018). Effect of Inspiratory Muscle Training on Performance of Handball Athletes. Journal of Human Kinetics, 63(1), 43-51.

Harver, A., Mahler, D. A., \& Daubenspeck, J. A. (1989). Targeted inspiratory muscle training improves respiratory muscle function and reduces dyspnea in patients with chronic obstructive pulmonary disease. Annals of Internal Medicine, 111(2), 117-124.

Jung, J. H., \& Kim, N. S. (2015). The effect of progressive high-intensity inspiratory muscle training and fixed high-intensity inspiratory muscle training on the asymmetry of diaphragm thickness in stroke patients. Journal of Physical Therapy Science, 27(10), 3267-3269. 
Karvonen, J. (2015). Importance of Warm-Up and Cool Down on Exercise Performance. In karger.com (pp. 189-214).

Kera, T. (2002). Measurement of respiratory muscle strength. Rigakuryoho Kagaku, 17(4), 265-271. https://doi.org/10.1589/rika.17.265

Lomax, M. E., \& McConnell, A. K. (2003). Inspiratory muscle fatigue in swimmers after a single 200 m swim. Journal of Sports Sciences, 21(8), 659-664.

McConnell AK. (2011). Breathe Strong, Perform Better. Human Kinetics.

Morse, M., Schlutz, F. W., \& Cassels, D. E. (1949). Relation of Age to Physiological Responses of the Older Boy (10-17 Years) to Exercise. Journal of Applied Physiology, 1(10), 683-709.

Okrzymowska, P., Kurzaj, M., Seidel, W., \& Rożek-Piechura, K. (2019). Eight weeks of inspiratory muscle training improves pulmonary function in disabled swimmersA randomized trial. International Journal of Environmental Research and Public Health, 16(10).

Özdal, M. (2016). Acute effects of inspiratory muscle warm-up on pulmonary function in healthy subjects. Respiratory Physiology and Neurobiology, 227, 23-26.

Özdal, M., Bostanci, Ö., Dağlioğlu, Ö., Ağaoğlu, S. A., \& Kabadayi, M. (2016). Effect of respiratory warm-up on anaerobic power. Journal of Physical Therapy Science, 28(7), 2097-2098.

Özdal, M., Dağlıoğlu, Ö., Demir, T., \& Özkul, N. (2014). Aerobik antrenmanın arteriyel hemoglobin oksijen satürasyonu üzerine etkisi. Spor ve Performans Araştırmaları Dergisi, 5(1), 27-34.

Öztütüncü, S., \& Özdal, M. (2019). Chronic Effect of Inspiratory Muscle Training to Maximal Expiratory Pressure in Sedentary Healthy Boys. Oapub.Org, 1-7.

Ranatunga, K. W., Sharpe, B., \& Turnbull, B. (1987). Contractions of Human Skeletal Muscle at Different Temperatures. In J. Physiol (Vol. 390).

Romer, L. M., McConnell, A. K., \& Jones, D. A. (2002). Effects of inspiratory muscle training upon recovery time during high intensity, repetitive sprint activity. International Journal of Sports Medicine, 23(5), 353-360.

Sheel, A. W., Derchak, P. A., Morgan, B. J., Pegelow, D. F., Jacques, A. J., \& Dempsey, J. A. (2001). Fatiguing inspiratory muscle work causes reflex reduction in resting leg blood flow in humans. Journal of Physiology, 537(1), 277-289.

Smith, D., Holmes, P., Whitemore, L., Collins, D., \& Devonport, T. (2001). The Effect of Theoretically-Based Imagery Scripts on Field Hockey Performance. Journal of Sport Behavior, 24(4), 408-419.

St Croix, C. M., Morgan, B. J., Wetter, T. J., \& Dempsey, J. A. (2000). Fatiguing inspiratory muscle work causes reflex sympathetic activation in humans. Journal of Physiology, 529(2), 493-504.

Volianitis, S., Mcconnell, A. K., \& Jones, D. A. (2001). Assessment of maximum inspiratory pressure: Prior submaximal respiratory muscle activity ('warm-up') enhances maximum inspiratory activity and attenuates the learning effect of repeated measurement. Respiration, 68(1), 22-27. 
Vural, M., Özdal, M., \& Pancar, Z. (2019). Effects of inspiratory muscle training on respiratory functions and respiratory muscle strength in Down syndrome: A preliminary study. Isokinetics and Exercise Science, 27(4), 283-288.

Williams, J. S., Wongsathikun, J., Boon, S. M., \& Acevedo, E. O. (2002). Inspiratory muscle training fails to improve endurance capacity in athletes. Medicine and Science in Sports and Exercise, 34(7), 1194-1198.

Wright, V., \& Johns, R. J. (1961). Quantitative and Qualitative Analysis of Joint Stiffness in Normal Subjects and in Patients with Connective Tissue Diseases. Annals of the Rheumatic Diseases, 20(1), 36-46. 
Nahsen Avci, Mustafa Özdal, Mehmet Vural

INFLUENCE OF INSPIRATORY MUSCLE WARM-UP EXERCISE

ON FIELD HOCKEY DRAG-FLICK AND SHOOTING PERFORMANCE

Creative Commons licensing terms

Authors will retain the copyright of their published articles agreeing that a Creative Commons Attribution 4.0 International License (CC BY 4.0) terms will be applied to their work. Under the terms of this license, no permission is required from the author(s) or publisher for members of the community to copy, distribute, transmit or adapt the article content, providing a proper, prominent and unambiguous attribution to the authors in a manner that makes clear that the materials are being reused under permission of a Creative Commons License. Views, opinions and conclusions expressed in this research article are views, opinions and conclusions of the author(s). Open Access Publishing Group and European Journal of Physical Education and Sport Science shall not be responsible or answerable for any loss, damage or liability caused in relation to/arising out of conflict of interests, copyright violations and inappropriate or inaccurate use of any kind content related or integrated on the research work. All the published works are meeting the Open Access Publishing requirements and can be freely accessed, shared, modified, distributed and used in educational, commercial and non-commercial purposes under a Creative Commons attribution 4.0 International License (CC BY 4.0). 